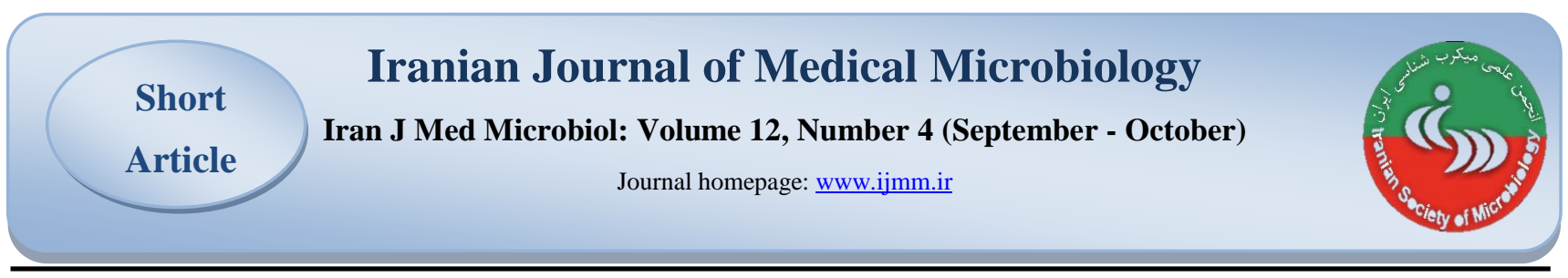

\title{
Antibiotic Resistance Among Escherichia coli, Pseudomonas aeruginosa and Acinetobacter baumannii Isolates Obtained From Shiraz Nemazi Hospital ICU Wards
}

\author{
Reza Khashei*, Zahra Navabi, Samaneh Mohebi, Naser Samadi
}

Department of Bacteriology and Virology, School of Medicine, Shiraz University of Medical Sciences, Shiraz, Iran

\section{Article Information}

\section{Article history:}

Received: 2018/07/10

Accepted: 2018/09/10

Available online: $2018 / 11 / 23$

\section{Article Subject:}

Antibiotic Resistance

IJMM 2018; 12(4): 294-300

Corresponding author:

\section{Reza Khashei}

Department of Bacteriology and Virology, School of Medicine, Shiraz University of Medical Sciences, Shiraz, Iran

Email:

khasheir@sums.ac.ir

Use your device to scan and read the article online

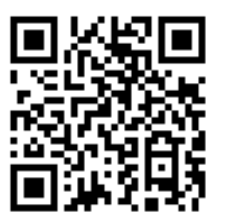

\section{Abstract}

Background and Aims: The monitoring of the causative agents of nosocomial infections (Nis), particularly in the Intensive Care Unit (ICU) ward to detect any change in pattern of infection and their resistance profile are crucial. The aim of this study was to investigate the antibiotic resistance pattern among Gram-negative rods isolated from inpatients in different wards of ICU in Shiraz, Iran.

Materials and Methods: In this cross-sectional study from Jaunary to June 2017, 91 different clinical samples were collected from Nemazi teaching hospital ICU wards. After confirming all the isolates by the conventional microbiologic methods, their antimicrobial susceptibility pattern against 11 antibiotics were investigated using the disk diffusion test. Extended-spectrum $\beta$-lactamase (ESBL) production was also examined.

Results and Conclusions: The isolated bacteria were Acinetobacter baumannii ( $\mathrm{n}=72$, $79.1 \%)$, Pseudomonas aeruginosa $(\mathrm{n}=14,15.4 \%)$, and Escherichia coli $(\mathrm{n}=5,5.5 \%)$. The highest and the lowest resistance rates were observed against ampicillin (100\% and 95.8\%) among $P$. aeruginosa and $A$. baumannii and imipenem and amikacin (0\%) among $P$. aeruginosa and $E$. coli isolates, respectively. The frequency of multidrug-resistant (MDR) and ESBL-producing isolates was found $84.6 \%$ and $19.8 \%$, respectively. Of the MDR isolates, $23.4 \%$ were ESBL producers. A significant difference was determined between ESBL production and MDR isolates.

Regarding the high rate of antimicrobial resistance among clinical isolates in the study area, the antibiotic susceptibility results may be a useful guide for empirical therapy used by physicians.

Keywords: Nosocomial infections, ICU, Antimicrobial Resistace, Iran

Copyright $\odot 2018$ Iranian Journal of Medical Microbiology. All rights reserved.

How to cite this article:

Khashei R, Navabi Z, Mohebi S, Samadi N. Antibiotic Resistance Among Escherichia coli, Pseudomonas aeruginosa and Acinetobacter baumannii Isolates Obtained From Shiraz Nemazi Hospital ICU Wards . Iran J Med Microbiol. 2018; 12 (4):294-300 


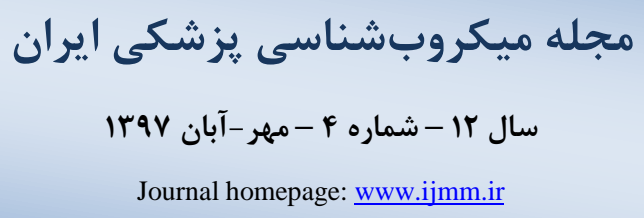

\section{بررسى مقاومت آنتىبيوتيكى ايزولههاى اشريشيا كلى، سودوموناس آئروزينوزا و اسينتوياكتر}

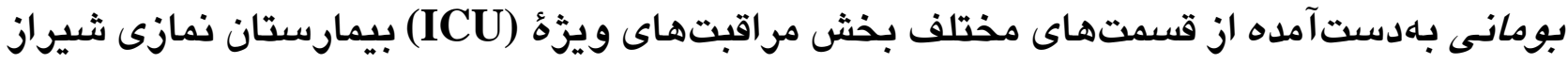
رضا خاشعى"، زهرا نوابى، سمانه محبى، ناصر صمدى فئى

\section{اطلاعات مقاله}

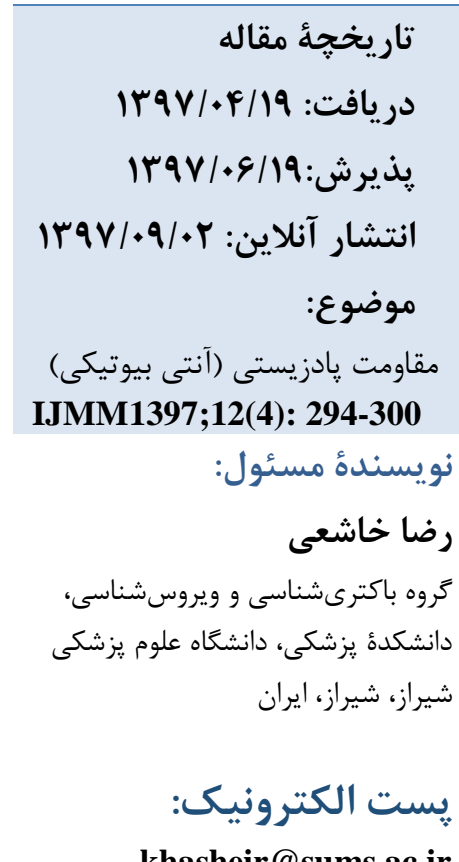

khasheir@sums.ac.ir

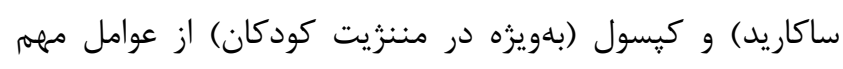
بيمارىزايى اين باكترى است كه باعث مقاومت سرمى و ورايدارى

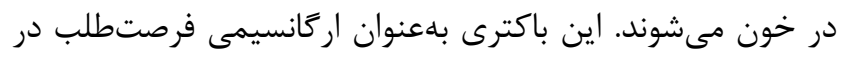

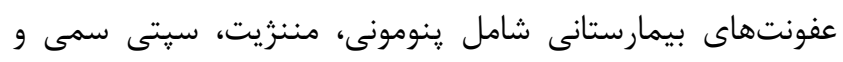
عفونتهاى زخمى نقش دارد.

سودوموناس آثروزينوزا (Pseudomonas aeruginosa) يك نيف دارد

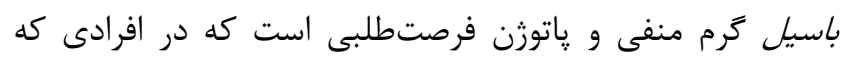

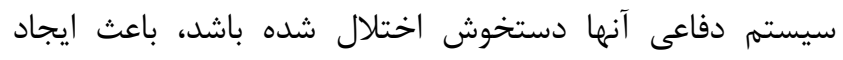

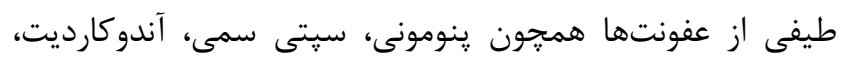

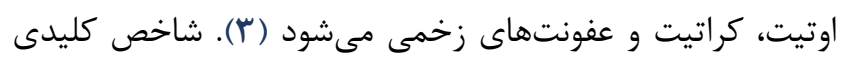

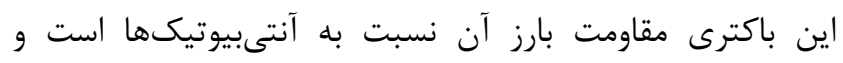

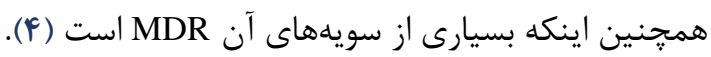

عفونتهاى بيمارستانى در ارتباط با افزايش موارد ابتلا،

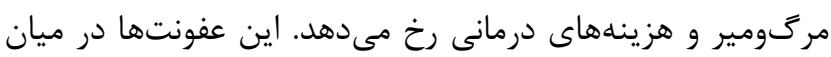

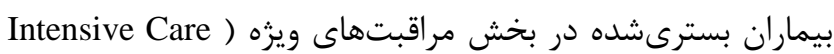

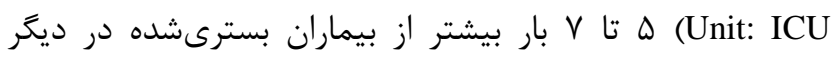

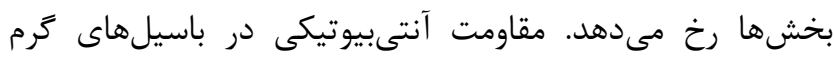

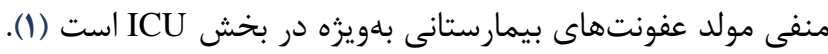

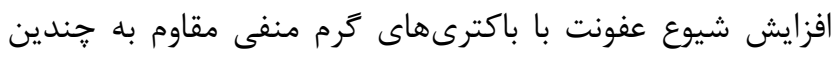

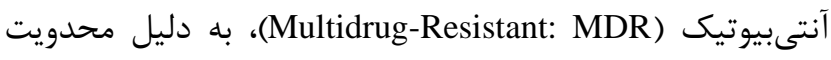
در درمان، تهديدى جدى براى بهداشت جهانى به شمار مىرود

اشريشيا كلى (Escherichia coli) يك باسيل كرم منفى و مهمترين عضو خانواده انتروباكترياسه است. اندوتوكسين (لييويلى بلى باسئ 


\section{ارزيابى حساسيت آنتىبيوتيكى}

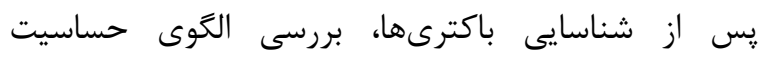

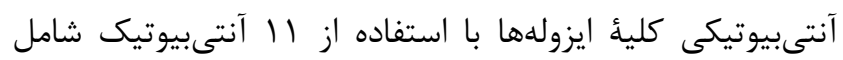

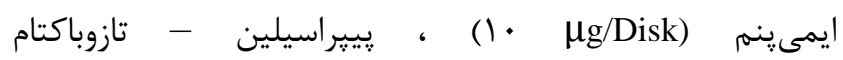
(بg/Disk) (ए بg/Disk) (A $\mu g /$ Disk)

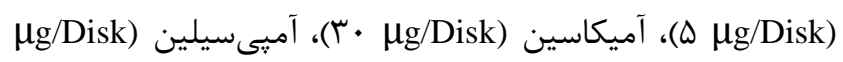

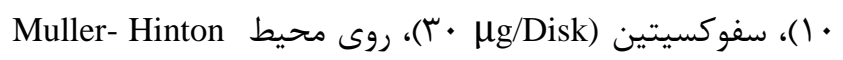

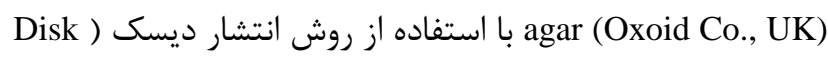
Clinical and Laboratory (diffusion Standards Institute (CLSI)

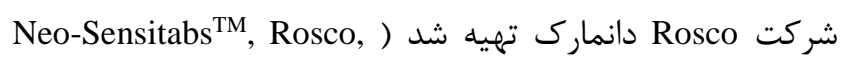
(Denmark سلسيوس، نتايج از نظر حضور هاله عدمرشد ( (inhibition

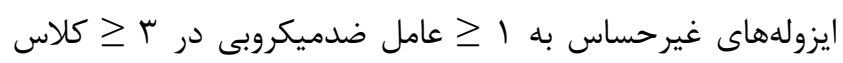

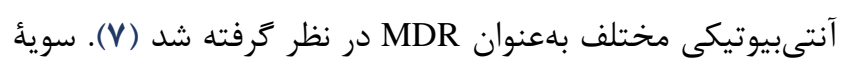
E. coli ATCC 25922 بيوتيكى بهعنوان كنترل كيفى استفاده شد.

شناسايى فنوتيبى

(ESBL)

ايزولههاى مقاوم به سفتازيديم و سفوتاكسيم (سفالوسيورين

نسل سوم) براى حضور آنزيمهاى بتالاكتاماز وسيعالطيف (ESBL)

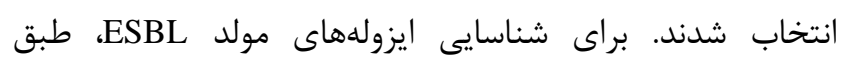

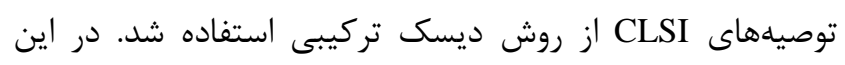

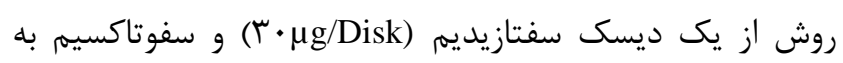

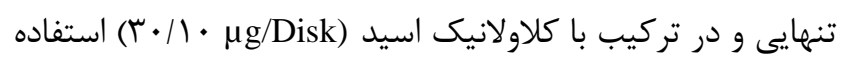

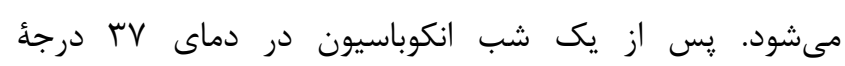

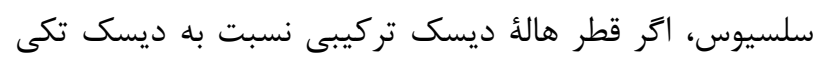

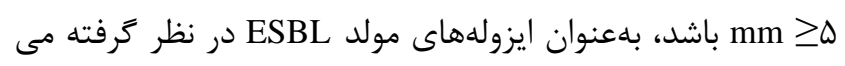

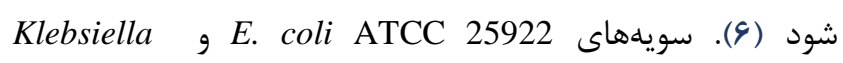
pneumoniae ATCC 700603

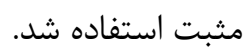
آناليز آمارى آنائف آناليز آمارى متغيرهاى مطالعه و آزمون مجذور مربع (2) بالئ

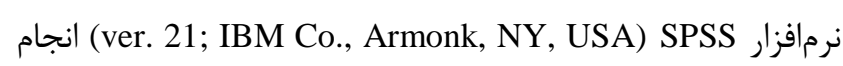
شد. نتايج بهدستآمده در قالب آمار توصيفى و بر حسب فراوانى
كونهاى جنس /سينتوباكتر (Acinetobacter) شامل

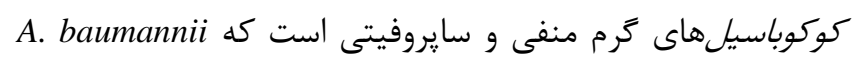

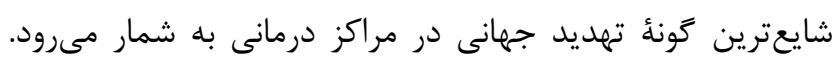

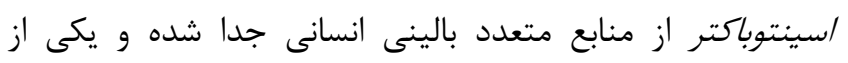

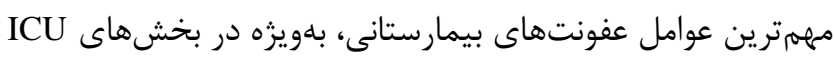

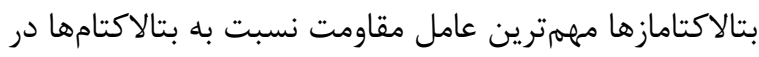

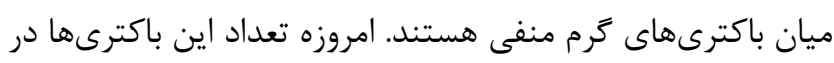

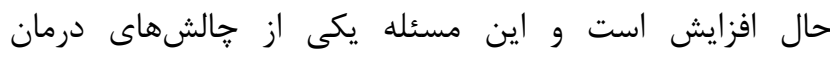

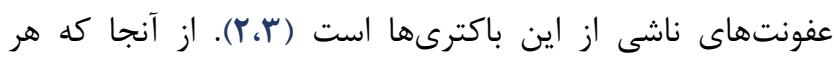

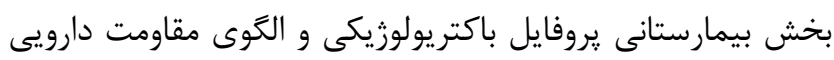

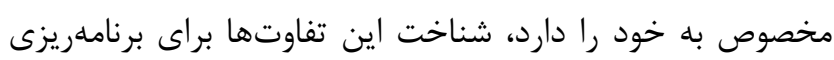

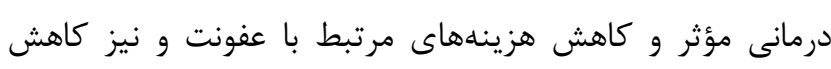

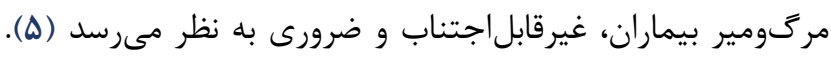

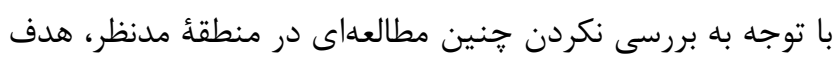

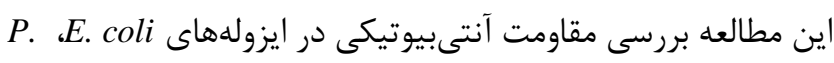
A. baumannii و aeruginosa قسمتهاى مختلف بخش ICU بيمارستان آموزشى نمازى دانشعاه علوم يزشكى شيراز است. مواد و روشها جمعيت مطالعه

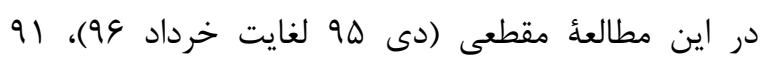

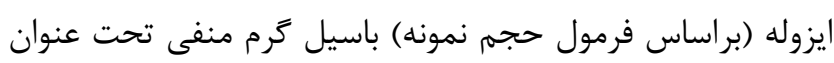
A. baumannii و P. aeruginosa, E. coli بيماران بسترىشده در قسمتهاى مختلف بخش ICU جمع آورى،

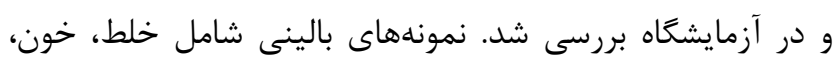

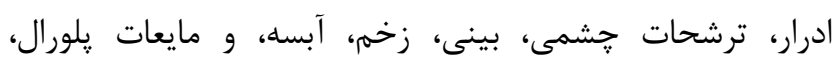

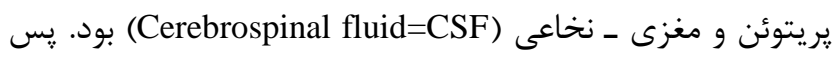

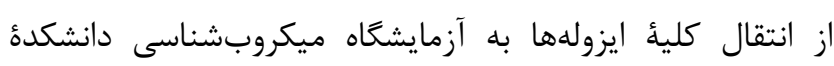
يزشكى شيراز و كشت مجدد در محيطهاى (Merck, Germany) و MacConkey Agar(Merck, Germany) و Blood Agar

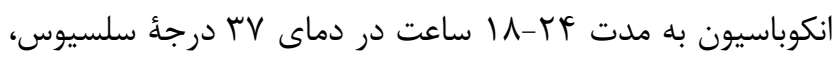

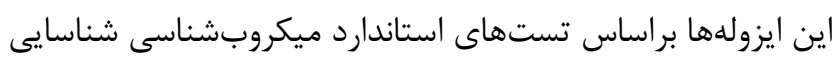

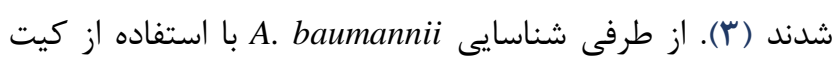

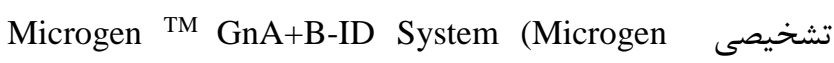
Bioproducts Ltd, U.K) 
نمونه به زنان مربوط بود. سن افراد از r ماه تا •و سال بود.

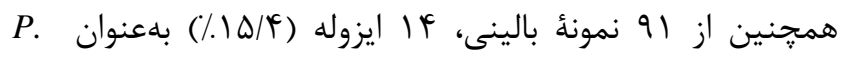

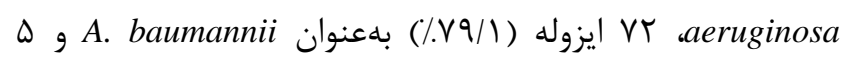

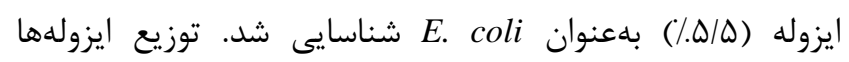
براساس قسمتهاى بخش ICU در جدول ا نشان داده شده است.

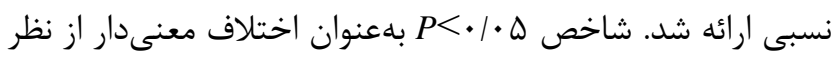
آمارى در نظر كرفته شد.

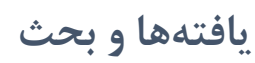

جمعيت مطالعهشده و ايزوله هاى باكتريايى ونحي

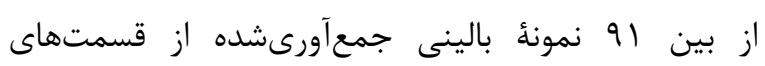

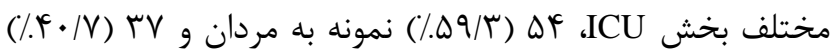

جدول ا. توزيع فراوانى ايزولههاى باكتريايى بر حسب قسمتهاى مختلف بخش ICU

\begin{tabular}{|c|c|c|c|c|}
\hline باكترى & $\begin{array}{c}\text { P. aeruginosa } \\
\text { تعداد }\end{array}$ & $\begin{array}{c}\text { A. baumannii } \\
\text { تعداد }\end{array}$ & $\begin{array}{c}\text { E. coli } \\
\text { تعداد }\end{array}$ & تعداد (درصد كل) \\
\hline اوررانس & . & r & 1 & $r(\% / r / \Gamma)$ \\
\hline عمومى & r & $\wedge$ & . & $1 \cdot(\% / 11)$ \\
\hline داخلى بزر كسالان & $r$ & 1. & 1 & If $(\% / 1 Q / \mathcal{F})$ \\
\hline جراحى مغز & · & $\Delta$ & 1 & $8(1 / 8 / 9)$ \\
\hline داخلى نوزادان & 1 & 14 & · & $10(\% / 9 / \Delta)$ \\
\hline جراحى نوزادان & $r$ & 9 & · & $\|(\% / r / 1)$ \\
\hline جراحى & 1 & r & . & $f(\% / F / F)$ \\
\hline مركزى & . & r & . & $r(\% / r / T)$ \\
\hline داخلى اطفال & $r$ & 19 & 1 & $19(\% / r \cdot 9)$ \\
\hline جراحى اطفال & $r$ & $r$ & 1 & $\mathrm{~V}(\% \mathrm{~V} / \mathrm{V})$ \\
\hline
\end{tabular}

بودند. در دو مطالعه روى عفونتهاى بيمارستانى در بخشهاى

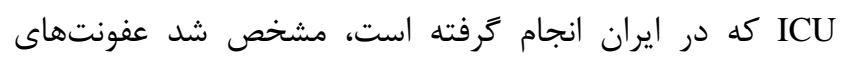

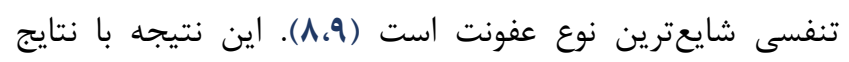
مطالعة حاضر همخوانى دارد.

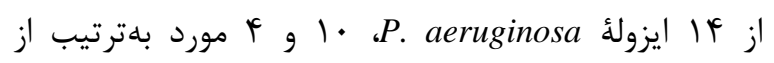

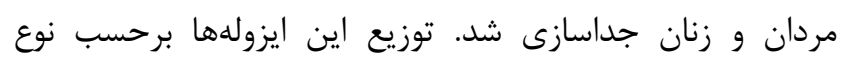

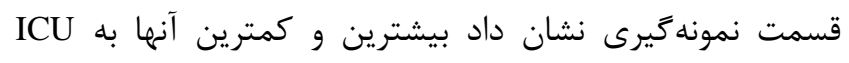

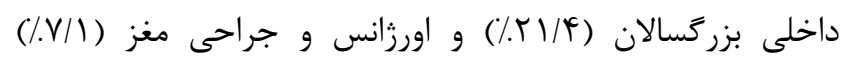

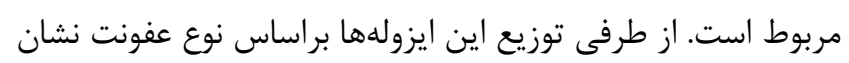

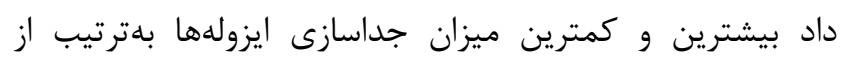

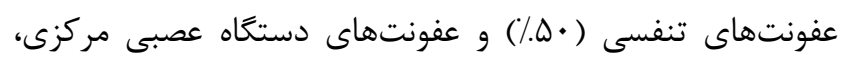

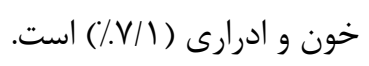

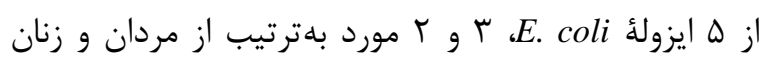

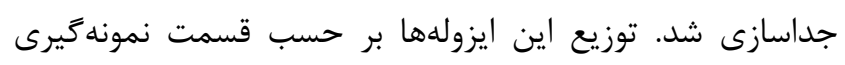

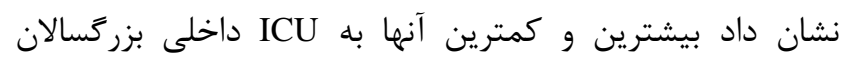

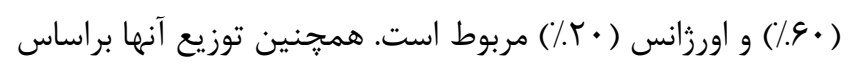

در بررسى باسيلهاى گرم منفى جداشده از قسمتهاى

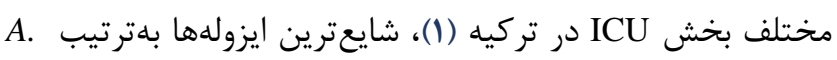
Pa aeruginosa gamannii جداشده با اين مطالعه همسو است. از طرفى توزيع ايزولها ونها

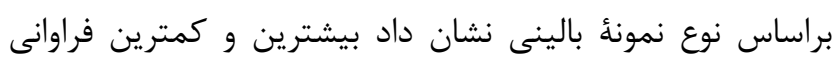

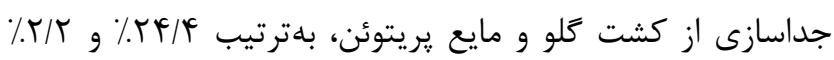

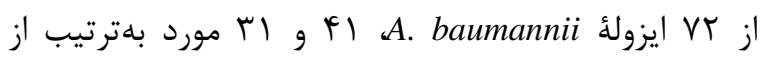

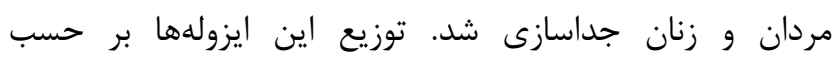

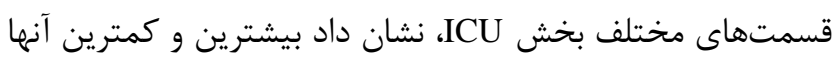

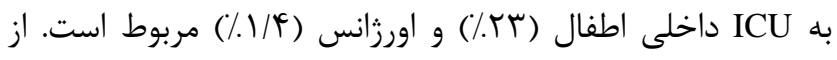

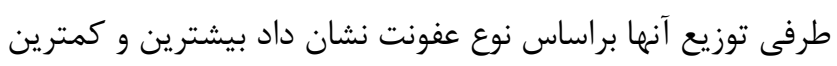

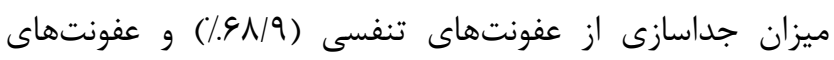

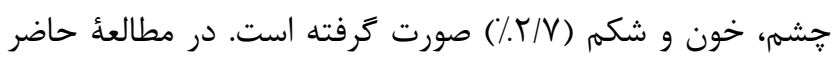

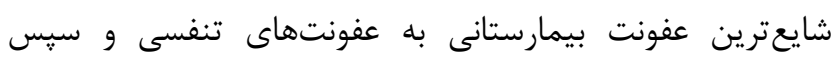

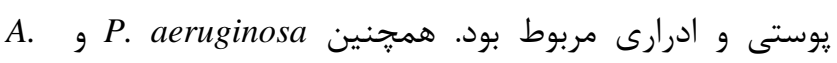
شaumannii 
مقاومت ضدميكروبى در ايزولههاى باكتريايى

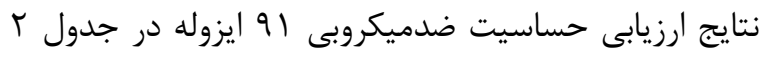

نوع عفونت نشان داد بيشترين و كمترين ميزان جداسازى ايزولهها

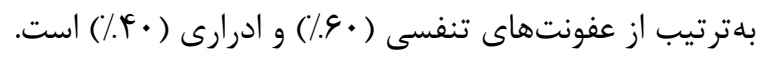

ارائه شده است.

جدول r. الكَوى مقاومت آنتى بيوتيكى باكترى هاى جداشده از عفونتهاى مختلف براساس نتايج انتشار ديسك آند

\begin{tabular}{|c|c|c|c|}
\hline $\begin{array}{c}\text { آنتى بيوتيك } \\
\text { باكترى }\end{array}$ & $\begin{array}{l}\text { P. aeruginosa } \\
\text { تعداد(درصد) }\end{array}$ & $\begin{array}{l}\text { A. baumannii } \\
\text { تعداد(درصد) }\end{array}$ & $\begin{array}{c}\text { E. coli } \\
\text { نعداد(درصد) }\end{array}$ \\
\hline IMI & · & $r \varphi(/ . \Delta \cdot)$ & - \\
\hline PITZ & $r(/ .1 F / T)$ & $r \wedge(/ /$ r / $/ 9)$ & $1(\% / \cdot)$ \\
\hline CTX & $9(1.94 / \pi)$ & $\Delta \varphi(/ / V \vee / \Lambda)$ & $F\left(\% / \Lambda^{*}\right)$ \\
\hline CAZ & $1(/ . V / 1)$ & Fr $(/ . \Delta \Lambda / \Gamma)$ & $r(\% .9 \bullet)$ \\
\hline $\mathrm{AZT}$ & $9(/ F Y / Q)$ & $\Delta \varphi(/ / V \vee / \wedge)$ & $r(\% .9 \bullet)$ \\
\hline CIP & $1(/ / V / 1)$ & $r q(/ . \Delta F / T)$ & $r(\% \varphi \cdot)$ \\
\hline GEN & $\Delta(/ . r \Delta / V)$ & fil $(1 . \Delta 9 / 9)$ & $1(\% \cdot r \cdot)$ \\
\hline LEVOF & $1(/ / V / 1)$ & $\operatorname{rr}(/ / K \mathcal{K} / \mathcal{K})$ & $r\left(\% F_{*}\right)$ \\
\hline AMI & $1(/ . V / 1)$ & $r \varphi(/ . \Delta \cdot)$ & · \\
\hline AMP & $1 f(/ .1 \cdots)$ & $99(/ .90 / 1)$ & $F(\% \cdot \wedge \cdot)$ \\
\hline $\mathrm{CFO}$ & $I T(/ . \wedge \Delta / V)$ & $9 \Delta(/ .9 \cdot / r)$ & $r\left(\% . \varphi_{\bullet}\right)$ \\
\hline تعداد كل باكترى & 14 & Vr & $\Delta$ \\
\hline
\end{tabular}

اختصارات: IMI (ايمىينم)، PITZ (يبيراسيلين-تازوباكتام)، CTX (سفوتاكسيم)، CAM (سيكام)، CAZ (سفتازيديم)، AZT (ازترونام)، CIP (سييروفلوكساسين)، GEN (جنتامايسين)،

LEVOF

برخى مطالعات در همدان و اهواز، مقاومت به ايمىينه در

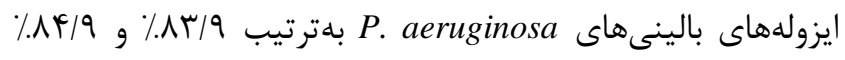
كزارش شده است (rا، با). از ه ايزوله

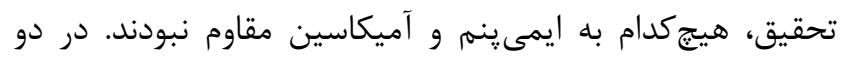

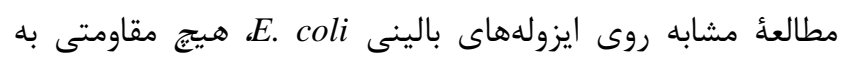

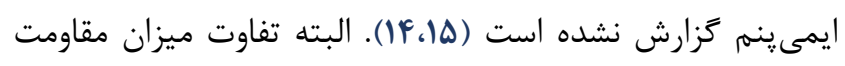

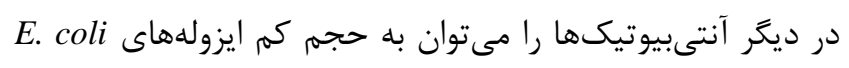
در مطالعهُ حاضر نسبت داد.

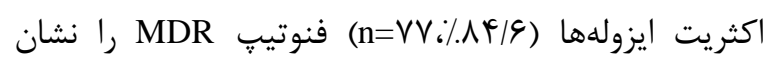

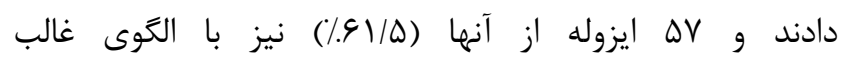

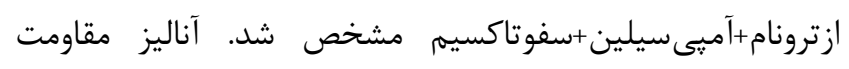

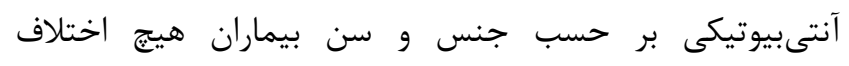

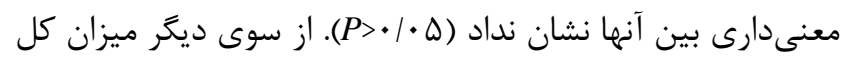

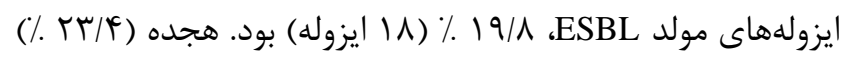

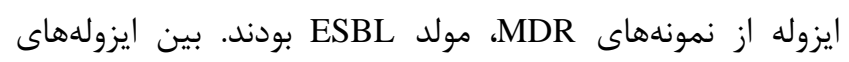
و توليد ESBL تفاوت معنى ESR

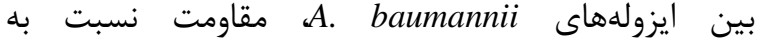

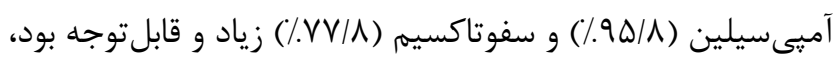

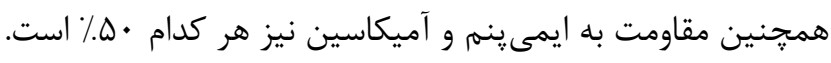

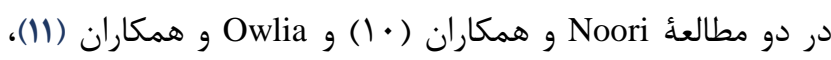

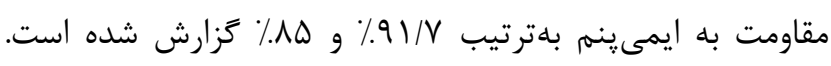
خوشبختانه حساسيت به ايمى ينهم و آميكاسين بهاعنوان مؤثرترين

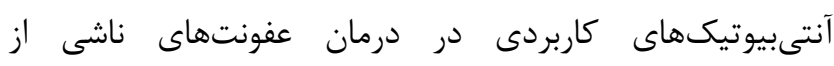
Acinetobacter

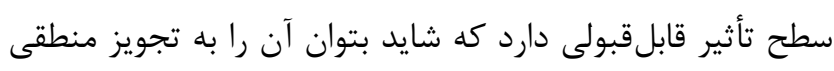

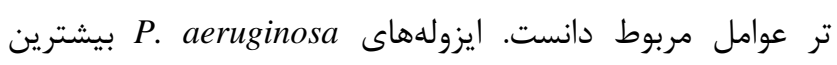

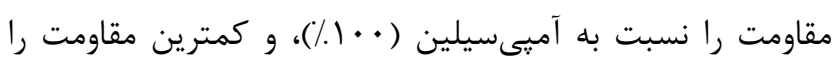

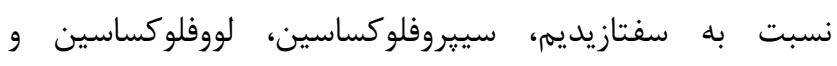

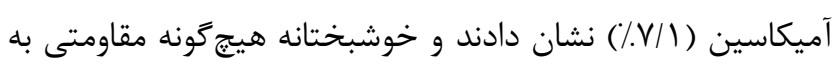

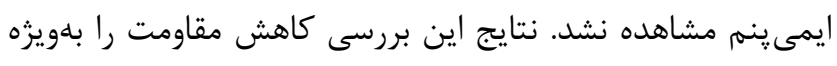

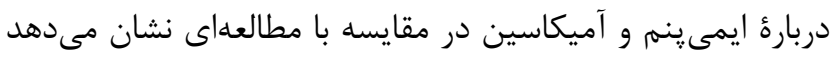

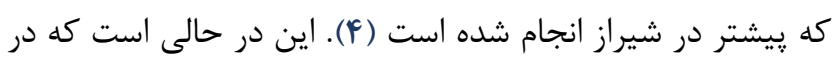




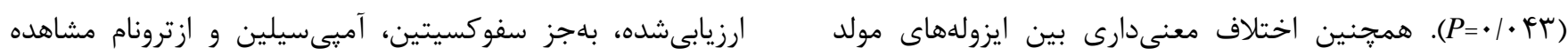
ESBL

جدول r. توزيع ايزولههاى مقاوم آنتىبيوتيك بر حسب توليد ESBL

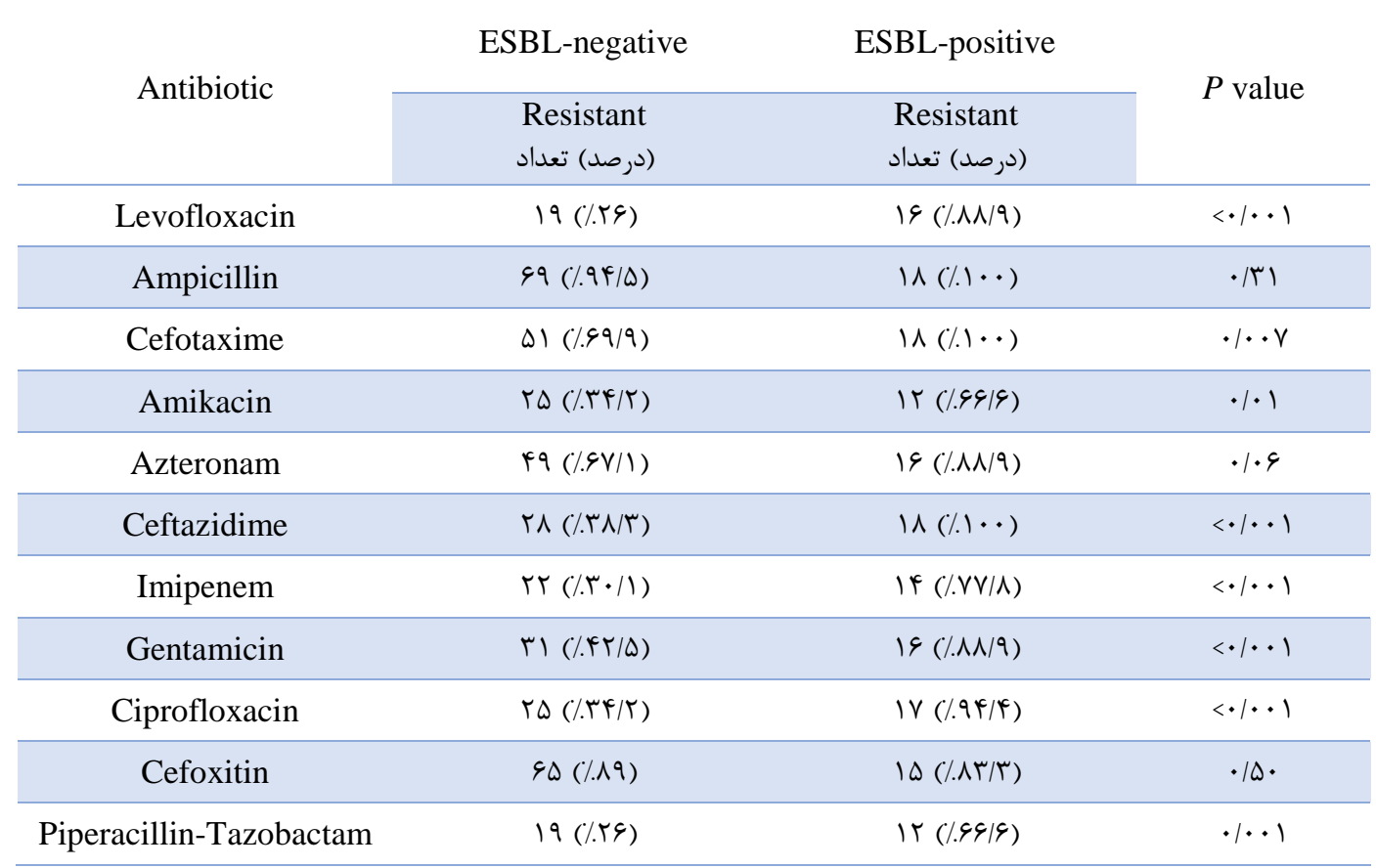

عفونتهاى بيمارستانى همجون كلبسيلا، انتروباكتر يا ديخر

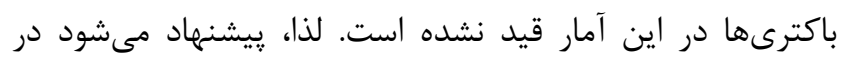

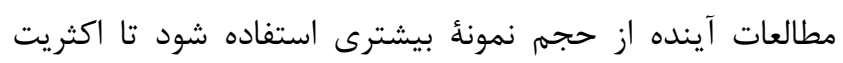

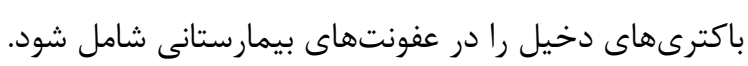

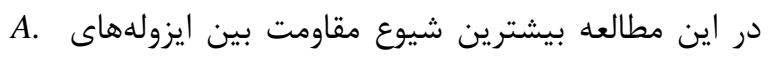
دaumannii

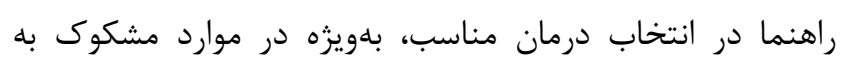

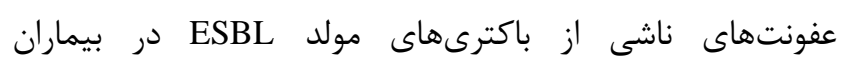

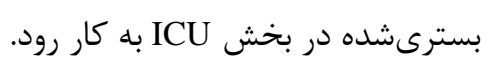
سياسگز إن

اين مقاله بركرفته از رسالهُ دكتراى حرفهاى خانم زهرا نوابى،

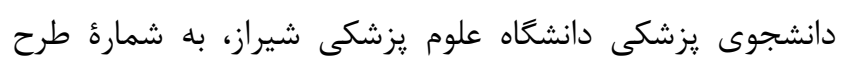

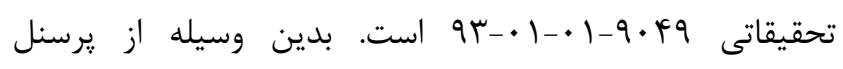

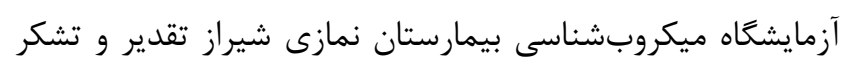
مىشود. تعارض منافع بين نويسندًان تعارض در منافع گزارش نشده است.

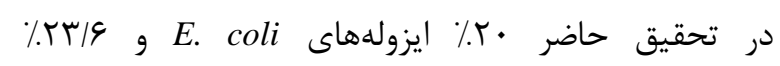

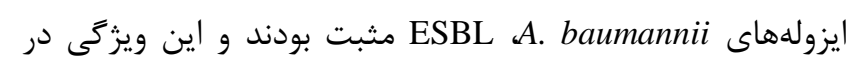
هيج يك از ايزولههاى P. aeruginosa مشاهده نشد، در حالى لئ كه

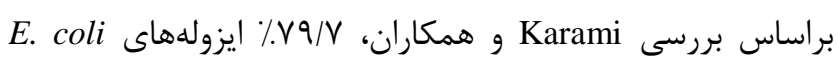

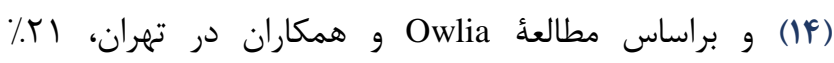

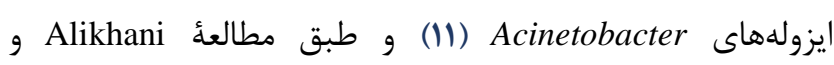

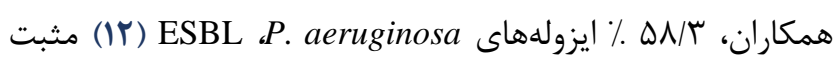

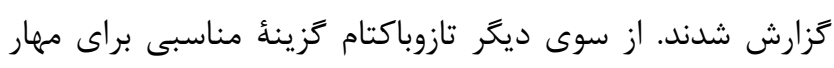

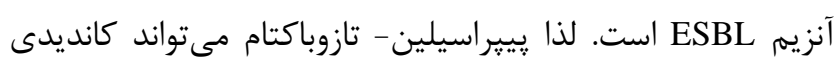

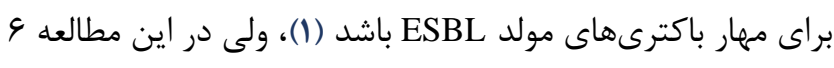

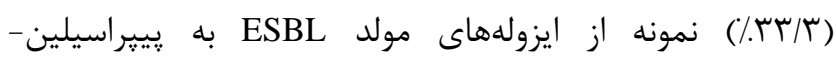
تازوباكتام حساس بودند. ميزان مقاومت ميكروبى نسبت به انواع آنتىبيوتيكها به به بهاب

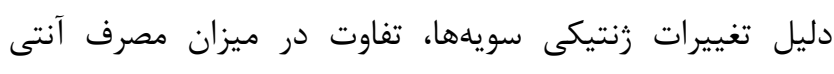

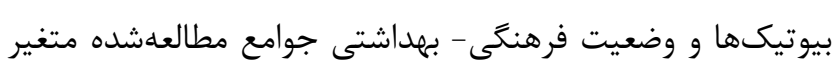

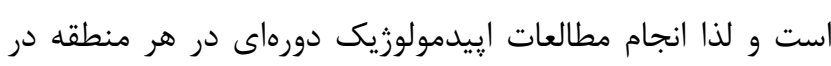

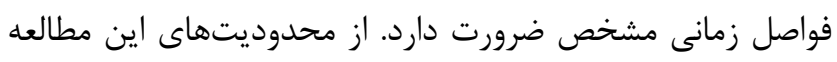

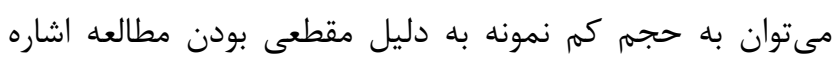

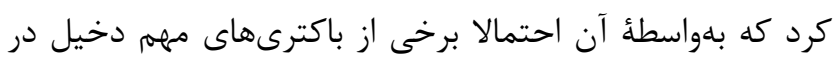


خاشعى و همكاران | مقاومت ضدميكروبى در باكترىهاى بلددست آمده از ICU

\section{References}

1. Kucukates E. Antimicrobial resistance among Gramnegative bacteria isolated from intensive care units in a Cardiology Institute in Istanbul, Turkey. Jap J Infect Dis. 2005;58(4):228-31. PMid:16116256

2. Cerceo E, Deitelzweig SB, Sherman BM, Amin AN. Multidrug-resistant gram-negative bacterial infections in the hospital setting: overview, implications for clinical practice, and emerging treatment options. Microb Drug Resist 2016;22(5):412-31. https://doi.org/10.1089/mdr.2015.0220

PMid:26866778

3. Mahon CR, Lehman D, Manuselis G. Textbook of Diagnostic Microbiology. 5th edition .New York: W. B. Saunders Company; 2015.

4. Yousefi-Avarvand A, Khashei R, Sedigh EbrahimSaraie H, Emami A, Zomorodian K, Motamedifar M. The frequency of exotoxin A and exoenzymes $\mathrm{S}$ and $\mathrm{U}$ genes among clinical isolates of Pseudomonas aeruginosa in Shiraz, Iran. Int J Mol Cell Med. 2015;4(3):167-73. PMid:26629485

5. Yildirim S, Nursal TZ, Tarim A, Torer N, Noyan T, Demiroglu YZ, et al. Bacteriological profile and antibiotic resistance: comparison of findings in a burn intensive care unit, other intensive care units, and the hospital services unit of a single center. J Burn Care Res. 2005; 26(6): 488-92. https://doi.org/10.1097/01.bcr.0000185454.72237.c6 PMid:16278563

6. Wayne PA. Clinical and Laboratory Standards Institute (CLSI). Performance Standards for Antimicrobial Susceptibility Testing 2015; 25th informational supplement. M100-S25.

7. Magiorakos AP, Srinivasan A, Carey RB, Carmeli Y, Falagas ME, Giske CG, et al. Multidrug-resistant, extensively drug-resistant and pandrug-resistant bacteria: an international expert proposal for interim standard definitions for acquired resistance. Clin Microbiol Infect. 2012;18:268-81. https://doi.org/10.1111/j.1469-0691.2011.03570.x

\section{PMid:21793988}

8. Rezaee H.H, Borji E, Mirzadi I, Salehi A, Sivandipur $\mathrm{H}$, Nekhei M, et al. A study on the rate and the types of hospital infection in the trauma ICU departments of Kerman hospitals in the first half of 1393. J Iran Soc Anaesthes Intens Care. 2015;37(91):166-71.

9. Ghafouri M, Hashemi SA, Azimian A, Garevani T, Seyed Sharifi SH. Evaluation of antibiotic resistance to bacteria isolated from patients with nosocomial infections hospitalized in Imam Reza in Bojnurd city in 2013. J Rafsanjan Univ Med Sci. 2015;14(7):599-610.

10. Noori M, Karimi A, Fallah F, Hashemi A, Alimehr S, Goudarzi $\mathrm{H}$, et al. High prevalence of metallo-beta- lactamase producing Acinetobacter baumannii isolated from two hospitals of Tehran, Iran. Arch Pediatr Infect Dis 2014;2(3):e15439. https://doi.org/10.5812/pedinfect.15439

11. Owlia P, Azimi L, Gholami A, Asghari B, Lari AR. ESBL-and MBL-mediated resistance in Acinetobacter baumannii: a global threat to burn patients. Infez Med. 2012;20(3):182-7. PMid:22992558

12. Alikhani MY, Tabar ZK, Mihani F, Kalantar E, Karami $\mathrm{P}$, Sadeghi M, et al. Antimicrobial resistance patterns and prevalence of blaPER-1 and blaVEB-1 genes among ESBL-producing Pseudomonas aeruginosa isolates in West of Iran. Jundishapur J Microbiol 2014;7(1):e8888. https://doi.org/10.5812/jjm.8888

13. Khosravi AD, Motahar M, Montazeri EA. The frequency of class1 and 2 integrons in Pseudomonas aeruginosa strains isolated from burn patients in a burn center of Ahvaz, Iran. PloS One 2017;12(8):e0183061. https://doi.org/10.1371/journal.pone.0183061

14. Karami P, Bazmamoun H, Sedighi I, Nejad ASM, Aslani MM, Alikhani MY. Antibacterial resistance patterns of extended spectrum $\beta$-lactamase-producing enteropathogenic Escherichia coli strains isolated from children. Arab J Gastroenterol 2017: 18(4):206-9. https://doi.org/10.1016/j.ajg.2017.11.004

15. Poursina F, Sepehrpour S, Mobasherizadeh S. Biofilm formation in nonmultidrug-resistant Escherichia coli isolated from patients with urinary tract infection in Isfahan, Iran. Adv Biomed Res 2018;7:40. https://doi.org/10.4103/abr.abr_116_17 